\title{
Changes in Macular Perfusion After ILUVIEN@ Intravitreal Implant for Diabetic Macular Edema: An OCTA Study
}

\author{
Maria Brambati - Enrico Borrelli - Luigi Capone - Lea Querques · \\ Riccardo Sacconi - Marco Battista · Francesco Bandello • \\ Giuseppe Querques (1)
}

Received: November 11, 2021 / Accepted: January 7, 2022 / Published online: January 28, 2022

(C) The Author(s) 2022

\begin{abstract}
Introduction: The aim of this study was to investigate changes in macular perfusion in patients affected by diabetic macular edema (DME) and treated with ILUVIEN ${ }^{\circledR}$ (fluocinolone acetonide intravitreal implant) $0.19 \mathrm{mg}$ using optical coherence tomography angiography (OCTA).

Methods: This was a retrospective cohort study that included patients aged $>18$ years with type 2 non-proliferative diabetic retinopathy (DR) and DME at baseline. All patients were treated with the ILUVIEN ${ }^{\circledR}$ implant. A minimum of two $6 \times 6-\mathrm{mm}$ OCTA scans were required to ensure that all cases had a baseline OCTA and an OCTA performed at 4 months of follow-up. Qualitative and quantitative comparisons were performed.
\end{abstract}

Results: Ten eyes from ten subjects were included in the analysis. Mean $( \pm$ standard deviation) age of the study cohort was $57.1 \pm$ 8.3 years. Mean parafoveal perfusion density

M. Brambati · E. Borrelli - L. Capone - L. Querques ·

R. Sacconi - M. Battista - F. Bandello ·

G. Querques $(\square)$

Department of Ophthalmology, University Vita-

Salute-IRCCS Ospedale San Raffaele, Via Olgettina

60, 20132 Milan, Italy

e-mail: giuseppe.querques@unisr.it
(PD) at baseline was $64.1 \pm 1.8 \%$ at baseline, increasing to $66.1 \pm 2.9 \%(p=0.013)$ at the 4-month follow-up visit. Mean parafoveal PD at baseline was $64.4 \pm 2.1 \%$, increasing to $65.2 \pm 2.6 \%(p=0.024)$ after 4 months. In the qualitative assessment, 60 regions (10 areas for each subject) were graded to assess changes in retinal perfusion between the baseline and follow-up visits. This assessment revealed that 24 regions $(40.0 \%)$ were characterized by a qualitative increase in perfusion after treatment, while $22(36.7 \%)$ and $14(23.3 \%)$ regions were featured by a stability and reduction in retinal perfusion, respectively.

Conclusion: OCTA analysis detects improvements in macular perfusion after treatment with ILUVIEN ${ }^{\circledR}$. This improvement in macular perfusion may be associated with corticosteroidrelated beneficial effects on leukostasis.

Keywords: Diabetes; Diabetic macular edema; Diabetic retinopathy; Fluocinolone acetonide; Iluvien; Optical coherence tomography angiography; Retinal perfusion 


\section{Key Summary Points}

Why carry out this study?

Diabetic macular ischemia is a relevant feature of diabetic retinopathy associated with visual outcome in these patients.

Optical coherence tomography angiography (OCTA) may allow qualitative and quantitative assessment of longitudinal changes in diabetic macular ischemia.

\section{What was learned from this study}

In this study, OCTA detected improvements in macular perfusion after treatment with fluocinolone acetonide.

This improvement in macular perfusion may be associated with corticosteroidrelated beneficial effects on leukostasis.

\section{INTRODUCTION}

Diabetic retinopathy (DR) is one of the most relevant complications of diabetes and also represents a leading cause of blindness and vision impairment in the Western world $[1,2]$. By 2050, it is expected that almost 16 million people aged $\geq 40$ years will be affected by DR in the USA, of whom 3.4 million will be affected by a vision-threatening form. Therefore, DR implies an enormous economic burden and social cost, resulting in an important impediment to the social and personal life of affected patients. [3, 4].

Diabetic macular edema (DME) is the main cause of diabetes-related vision loss, and it develops because of retinal vascular leakage in the macula. DME can be a complication at any stage of DR, although it more frequently affects patients in more advanced stages [5]. Although the pathophysiology of DME is complicated and multifactorial, this complication ultimately is secondary to an increase in the permeability of

retinal vessels secondary to endothelial damage, an increase in vascular endothelial growth factor (VEGF) levels and and a rise in the intraocular amount of inflammatory cytokines [6]. Therapeutic options for the management of DME may involve the blocking of VEGF signaling using intravitreal injections of anti-VEGF drugs $[7,8]$, as well as the inhibition of the inflammatory cascade through intravitreal injection of corticosteroids [9-11]. Among the latter treatments, ILUVIEN ${ }^{\circledR}$ (fluocinolone acetonide intravitreal implant) is a nonbiodegradable cylindrical tube injected in the vitreous through a 25-gauge needle, which is able to provide a sustained release of the steroid. The efficacy and safety of fluocinolone acetonide implants in patients with DME was demonstrated in the FAME study [12].

Assessment of DME has been significantly improved with the introduction of structural optical coherence tomography (OCT) which enables the detection of even small amounts of intraretinal fluid, as well as the identification of biomarkers of treatment response and visual outcome [6, 13-16]. OCT angiography (OCTA) is a relatively novel modality that non-invasively illustrates the retinal and choroidal microvasculature and is frequently employed in the management of patients with DR and DME [17-21]. More importantly, OCTA technology has been used to assess changes in retinal perfusion occurring after anti-VEGF treatment for DME [22].

The aim of this study was to investigate changes in macular perfusion in patients affected by DME and treated with ILUVIEN ${ }^{\circledR}$ using OCTA analysis.

\section{METHODS}

\section{Study Participants}

This was a retrospective cohort study that included patients aged $>18$ years with type 2 non-proliferative DR and DME in at least one eye who attended S. Raffaele Hospital-IRCCS, Milan, Italy. The study conformed with the Helsinki Declaration of 1964 and its later amendments, and was approved by the San 
Raffaele Scientific Committee. Informed consent was obtained from all individual participants included in the study.

Data were collected on patients with DME (central macular thickness $\geq 275 \mu \mathrm{m}$ on spectral domain OCT [SD-OCT] images) who were treated with the ILUVIEN ${ }^{\circledR}$ implant. Before the latter treatment, all enrolled eyes had been previously treated with both anti-VEGF and dexamethasone implant therapies. For inclusion in the study, all patients had to have had a minimum of two OCTA scans, one at baseline (range 1-5 days before treatment) and one at the 4-month follow-up. In addition, each visit had to have included measurement of bestcorrected visual acuity, dilated fundus biomicroscopy and structural OCT. Exclusion criteria included: (1) ocular comorbidities, such as retinal arterial or venous occlusion, age-related macular degeneration, inherited macular disease and posterior segment inflammation; and (2) presence of significant media opacities.

Patients underwent OCTA imaging using the PLEX Elite 9000 (Carl Zeiss Meditec Inc., Dublin, CA, USA) device. For each patient, $6 \times 6-\mathrm{mm}$ OCTA scans centered on the fovea were acquired.

\section{Quantitative Analysis}

For each patient, we first obtained the en face OCTA images of the superficial capillary plexus (SCP) at the instrument's default setting [23]. All OCTA B-scan images were checked for errors in automatic segmentation, and manual correction was made for all the identified segmentation errors. These images were exported and then imported into Fiji distribution of ImageJ (software version 2.0.0; National Institutes of Health, Bethesda, MD, USA; available at http:// rsb.info.nih.gov/ij/index.html) for processing and analysis [24].

The "global default" threshold was used to binarize images, as this threshold has been demonstrated to be the most accurate to correctly select the flow in OCTA images obtained in DR patients with and without DME [21]. For each resulting image, the perfusion density (PD) was measured as a unitless proportion of the number of pixels over the threshold divided by the total number of pixels in a region of interest. The binarized SCP images were also skeletonized to calculate the vessel length density (VLD) which was defined as the ratio between total pixels above the threshold in the skeletonized image and total number of pixels in the region of interest. These OCTA metrics (PD and VLD) were calculated after excluding the foveal avascular zone (FAZ) from the analysis. The FAZ was manually outlined in the original SCP scans, as previously described $[25,26]$, and the entire remaining procedure was automated by applying an ImageJ macro. The main outcome measures were: (1) parafoveal and perifoveal SCP PD; (2) parafoveal and perifoveal SCP VLD.

\section{Qualitative Analysis}

Baseline and follow-up OCTA original (i.e. before binarization) images were reviewed by two expert graders (MB and $\mathrm{EB}$ ) who performed the grading separately. Graders were masked for the images and patient information. Graders later met to compare level of agreement, and disagreements were resolved by further discussion and open adjudication to yield a single assessment for each case. For those cases on which the two graders did not agree on a single consensus result, the final decision was made by the director of the San Raffaele Medical Retina and Imaging Unit (GQ).

For each patient, six regions $(1.0 \times 1.0-\mathrm{mm}$ square) were selected by a third author (RS). The grading process was aimed at evaluating changes in retinal perfusion on the basis of the quantity of arterioles or venules that disappeared or reappeared in each of these analyzed regions between baseline and follow-up visits. After this assessment, graders categorized regions into areas showing an increase, decrease or stability in retinal perfusion.

\section{Statistical Analysis}

Statistical calculations were performed using the Statistical Package for Social Sciences software package, version 20.0 (SPSS IBM Corp., Armonk, NY, USA). 
Quantitative variables were expressed as the mean and standard deviation (SD), and categorical variables were presented as counts. The paired-samples $t$-test was used to compare quantitative values at following visits. The chosen level of statistical significance was $p<0.05$.

\section{RESULTS}

Ten eyes from ten subjects were included in analysis. Mean $( \pm \mathrm{SD}$ ) age was $57.1 \pm 8.3$ (range $32-71$ ) years. Of the ten eyes included in the assessments, eight had a mild non-proliferative DR form, and two were affected by a moderate non-proliferative form. At enrollment, all enrolled eyes displayed the presence of DME; after 4 months, DME was absent in seven of the ten eyes. Mean number of anti-VEGF and dexamethasone implant treatments before the
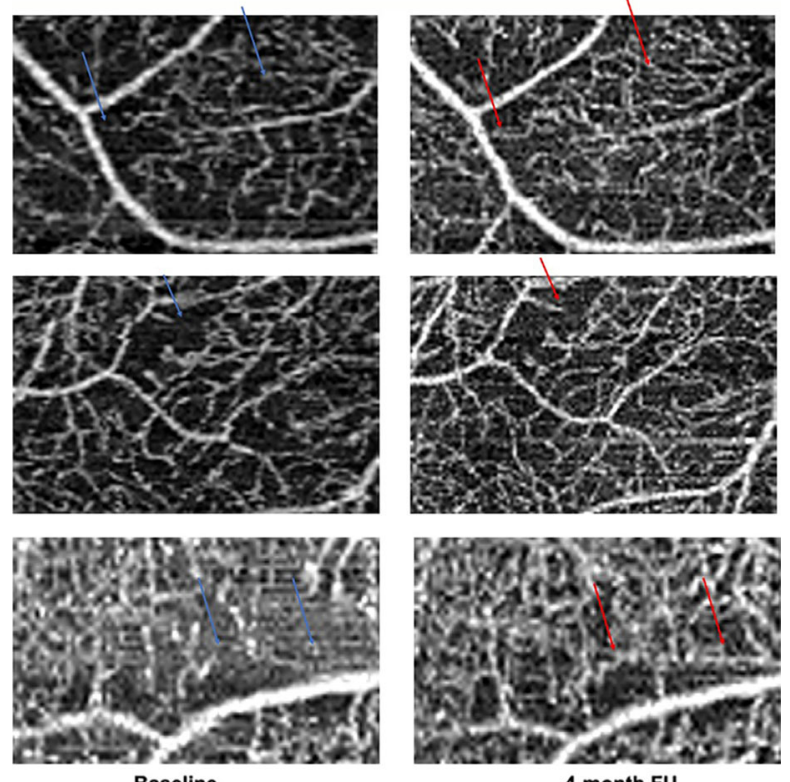

Fig. 1 OCTA images from three patients with diabetic retinopathy (one for each row). OCTA images at baseline (left column) and at 4-month follow-up visit (right column) in three patients affected by diabetic macular edema and treated with ILUVIEN ${ }^{\circledR}$ intravitreal implant. Blue (at baseline) and red (at the 4-month follow-up visit) arrows highlight vessels reperfused after treatment
ILUVIEN ${ }^{\circledR}$ implant was $9.4 \pm 2.7$ and $1.7 \pm 0.4$, respectively.

The signal strength index of the included scans was $8.4 \pm 0.7$ (range 7-10).

In the quantitative analysis, mean $( \pm \mathrm{SD})$ parafoveal SCP PD at baseline was $64.1 \pm 1.8 \%$, increasing to $66.1 \pm 2.9 \%$ at the 4 -month follow-up $(p=0.013)$. Mean perifoveal SCP PD at baseline was $64.4 \pm 2.1 \%$, increasing to $65.2 \pm 2.6 \%(p=0.024)$. No statistically significant changes in VLD were found in both the parafoveal $(9.1 \pm 0.8 \%$ at baseline and $9.3 \pm$ $0.8 \%$ at the follow-up visit, $p=0.630$ ) and perifoveal $(9.2 \pm 0.9 \%$ at baseline and $9.5 \pm 0.8 \%$ at the follow-up visit, $p=0.252$ ) regions.

In the qualitative assessment (Fig. 1), 60 regions were graded to assess changes in retinal perfusion between the baseline and follow-up visits. In this assessment, 24 regions (40.0\%) were characterized as showing a qualitative increase in perfusion after treatment, while 22 $(36.7 \%)$ and $14(23.3 \%)$ regions were featured by a stability and reduction in retinal perfusion, respectively.

\section{DISCUSSION}

This OCTA study was designed to assess the effect of the sustained-release fluocinolone acetonide intravitreal implant on macular perfusion in patients with DME. Overall, our qualitative and quantitative assessments demonstrated that this treatment may improve retinal perfusion in these eyes.

OCTA can identify retinal microvascular changes that would otherwise be undetectable using other imaging modalities (i.e. fundus photography and fluorescein angiography [FA]). Previous studies employing OCTA [27] demonstrated that a reduced macular perfusion may affect diabetic patients, even without signs of DR. More importantly, macular hypoperfusion may be considered to be an independent predictive factor for DR progression and vision loss [28-31]. Furthermore, data from a number of studies using distinct approaches (i.e. including OCTA) indicate that diabetic macular ischemia is a relevant pathological component to consider in eyes with DR. 
For example, the presence of macular ischemia in eyes with DME was revealed to have a prognostic role in eyes undergoing anti-VEGF intravitreal therapy [32, 33].

Based on the assumption that retinal perfusion plays a relevant role in the prognosis of patients with DR, two previous studies employed OCTA and fluorescein angiography to assess the changes in retinal perfusion occurring after anti-VEGF therapy in patients with DME [22, 34]. In one of these studies [22], the authors analyzed ten eyes of nine patients with severe non-proliferative DR or proliferative DR being treated with three injections of antiVEGF treatment. Based on their assessment, the authors concluded that the three injections of anti-VEGF did not result in improvement of retinal perfusion. However, these findings have been debated as evidence from an earlier study using fluorescein angiography may suggest that anti-VEGF therapy can improve retinal perfusion [35].

In a previous study carried out by our group, we assessed early modifications in retinal peripheral perfusion after treatment with intravitreal corticosteroids (i.e. dexamethasone [DEX] implant) for DME [36]. In this study, seven patients (9 eyes) with non-proliferative DR and DME were prospectively analyzed. In order to investigate variations in retinal perfusion occurring after DEX treatment, we quantified the ischemic index (ISI) on ultra-widefield FA images at baseline and at a mean $( \pm$ SD) of $10 \pm 2$ weeks following the DEX intravitreal injection. Consequently, we showed that DR eyes may be characterized by a significant early amelioration in retinal perfusion following a single DEX implant. In a following study [37], our group also investigated late changes in peripheral ischemia in subjects affected by DME and undergoing repeated DEX intravitreal implants over a period of 1 year. In the latter study, six eyes of five patients were retrospectively analyzed and the ISI was quantified on the ultra-widefield FA images at the baseline and the 1-year follow-up visits. The latter study showed that an improvement in retinal perfusion may still characterize DME eyes undergoing DEX treatment, even after 1 year following the initiation of treatment.
In the present study, using OCTA analysis, we add to the literature by reporting on the macular perfusion changes following treatment with ILUVIEN ${ }^{\circledR}$ in patients with DME. By combining the results of qualitative and quantitative analyses, we show that this treatment may be associated with a significant improvement in macular perfusion, in both the parafoveal and perifoveal regions. We may speculate that this improvement in macular perfusion may be secondary to a favorable corticosteroidrelated effect on leukocyte stasis (leukostasis). Leukostasis has been shown to be involved in DR development and progress as it stimulates retinal non-perfusion and vascular leakage [38, 39]. Specifically, diabetes has been shown to cause an increased activation of leukocytes with a following rise in the adhesion of these cells to vascular endothelium [38]. Therefore, a decline in retinal perfusion and intensification in leukocyte adhesion have been suggested to be two concurrent processes that share common metabolic factors and are strictly inter-related [39]. Considering that the intravitreal injection of corticosteroids may prevent leukocyte recruitment in the retina [39], we may thus come to the conclusion that our data may suggest a ILUVIEN ${ }^{\circledR}$ implant-related decline in leukocyte recruitment within retinal vessels.

Our study has a number of limitations, including its retrospective nature and the relatively small sample size. Future larger prospective longitudinal studies may further clarify the changes occurring in macular perfusion after treatment with ILUVIEN $₫$. Furthermore, we did not investigate changes occurring in the deep vascular complex as the assessment of this plexus may be significantly affected by segmentation errors in eyes with DME [21]. In addition, we did not provide an assessment of the modifications occurring in the perfusion of the retinal periphery after this treatment. However, previous reports [36, 37] have already reported on these modifications following intravitreal treatment with corticosteroids. 


\section{CONCLUSIONS}

In conclusion, this study investigated the modifications occurring in macular perfusion after treatment with the intravitreal ILUVIEN ${ }^{\circledR}$ implant over a 4-month period. We showed that this treatment may be associated with an improvement in macular perfusion, as assessed combining both a qualitative and quantitative analysis. Using a different imaging modality (OCTA in this study vs. FA in previous studies $[36,37])$, our data seem to corroborate the hypothesis that intravitreal corticosteroids may be associated with a significant improvement in retinal perfusion. This amelioration in macular perfusion may be associated with corticosteroidrelated beneficial effects on leukostasis.

\section{ACKNOWLEDGEMENTS}

Funding. No funding or sponsorship was received for this study or publication of this article.

Authorship. All named authors meet the International Committee of Medical Journal Editors (ICMJE) criteria for authorship for this article, take responsibility for the integrity of the work as a whole, and have given their approval for this version to be published.

Author Contributions. Conceptualization: Maria Brambati, Enrico Borrelli, Francesco Bandello and Giuseppe Querques. Methodology: Maria Brambati, Enrico Borrelli, Francesco Bandello and Giuseppe Querques. Formal analysis and investigation: Maria Brambati, Enrico Borrelli, Francesco Bandello and Giuseppe Querques. Writing (original draft preparation): Maria Brambati and Enrico Borrelli; Writing (review and editing): Maria Brambati, Enrico Borrelli, Luigi Capone, Lea Querques, Riccardo Sacconi, Marco Battista, Francesco Bandello and Giuseppe Querques. Supervision: Enrico Borrelli, Francesco Bandello and Giuseppe Querques.

Disclosures. Maria Brambati, Enrico Borrelli, Luigi Capone, Lea Querques, Riccardo Sacconi,
Marco Battista, Francesco Bandello and Giuseppe Querques have nothing to disclose.

Compliance with Ethics Guidelines. The study conformed with the Helsinki Declaration of 1964 and its later amendments, and was approved by the San Raffaele Scientific Committee. Informed consent was obtained from all individual participants included in the study.

Data Availability. The datasets generated during and/or analyzed during the current study are available from the corresponding author on reasonable request

Open Access. This article is licensed under a Creative Commons Attribution-NonCommercial 4.0 International License, which permits any non-commercial use, sharing, adaptation, distribution and reproduction in any medium or format, as long as you give appropriate credit to the original author(s) and the source, provide a link to the Creative Commons licence, and indicate if changes were made. The images or other third party material in this article are included in the article's Creative Commons licence, unless indicated otherwise in a credit line to the material. If material is not included in the article's Creative Commons licence and your intended use is not permitted by statutory regulation or exceeds the permitted use, you will need to obtain permission directly from the copyright holder. To view a copy of this licence, visit http://creativecommons.org/licenses/bync/4.0/.

\section{REFERENCES}

1. Cohen SR, Gardner TW. Diabetic retinopathy and diabetic macular edema. Dev Ophthalmol. 2016;55: 137-46. https://doi.org/10.1159/000438970.

2. Gardner TW, Antonetti DA, Barber AJ, LaNoue KF, Levison SW. Diabetic retinopathy: more than meets the eye. Surv Ophthalmol. 2002;47 Suppl 2: S253-62. https://doi.org/10.1016/S00396257(02)00387-9.

3. Saaddine JB, Honeycutt AA, Narayan K, Zhang X, Klein R, Boyle JP. Projection of diabetic retinopathy 
and other major eye diseases among people with diabetes mellitus: United states, 2005-2050. Arch Ophthalmol. 2008;126(12):1740-7.

4. Wang J-H, Ling D, Tu L, van Wijngaarden P, Dusting GJ, Liu G-S. Gene therapy for diabetic retinopathy: are we ready to make the leap from bench to bedside? Pharmacol Ther. 2017;173:1-18. https://doi.org/10.1016/j.pharmthera.2017.01.003.

5. [No authors listed]. Photocoagulation for diabetic macular edema. Early Treatment Diabetic Retinopathy Study report number 1. Early Treatment Diabetic Retinopathy Study research group. Arch Ophthalmol. 1985;103(12):1796-1806. https://doi.org/10.1001/archopht.1985. 01050120030015.

6. Vujosevic S, Torresin T, Berton M, Bini S, Convento E, Midena E. Diabetic macular edema with and without subfoveal neuroretinal detachment: two different morphologic and functional entities. Am J Ophthalmol. 2017;181:149-155. https://doi.org/10. 1016/j.ajo.2017.06.026.

7. Virgili G, Parravano M, Menchini FEJ. Anti-vascular endothelial growth factor for diabetic macular oedema. Cochrane Database Syst Rev. 2014;10: CD007419.

8. Heier JS, Bressler NM, Avery RL, et al. Comparison of aflibercept, bevacizumab, and ranibizumab for treatment of diabetic macular edema: extrapolation of data to clinical practice. JAMA Ophthalmol. 2016;134(1):95-9. https://doi.org/10.1001/ jamaophthalmol.2015.4110.

9. Boyer DS, Yoon YH, Belfort R, et al. Three-year, randomized, sham-controlled trial of dexamethasone intravitreal implant in patients with diabetic macular edema. Ophthalmology. 2014;121(10): 1904-14. https://doi.org/10.1016/j.ophtha.2014. 04.024 .

10. Kuppermann BD, Blumenkranz MS, Haller JA, et al. Randomized controlled study of an intravitreous dexamethasone drug delivery system in patients with persistent macular edema. Arch Ophthalmol. 2007;125(3):309-17. https://doi.org/10.1001/ archopht.125.3.309.

11. Sacconi R, Giuffrè C, Corbelli E, Borrelli E, Querques $\mathrm{G}$, Bandello F. Emerging therapies in the management of macular edema: a review. F1000Research. 2019;8:1413. f1000research.19198.1.

12. Campochiaro PA, Brown DM, Pearson A, et al. Long-term benefit of sustained-delivery fluocinolone acetonide vitreous inserts for diabetic macular edema. Ophthalmology. 2011;118(4):626-635. e2. https://doi.org/10.1016/j.ophtha.2010.12.028.
13. Wilkinson CP, Ferris FL, Klein RE, et al. Proposed international clinical diabetic retinopathy and diabetic macular edema disease severity scales. Ophthalmology. 2003;110(9):1677-82. https://doi.org/ 10.1016/S0161-6420(03)00475-5.

14. Vujosevic S, Berton M, Bini S, Casciano M, Cavarzeran F, Midena E. Hyperreflective retinal spots and visual function after anti-vascular endothelial growth factor treatment in center-involving diabetic macular edema. Retina. 2016;36(7):1298-308. https://doi.org/10.1097/IAE.0000000000000912.

15. Vujosevic S, Midena E, Pilotto E, Radin PP, Chiesa L, Cavarzeran F. Diabetic macular edema: correlation between microperimetry and optical coherence tomography findings. Invest Ophthalmol Vis Sci. 2006;47(7):3044-51. https://doi.org/10.1167/iovs. 05-1141.

16. Borrelli E, Grosso D, Barresi C, et al. Long-term visual outcomes and morphologic biomarkers of vision loss in eyes with diabetic macular edema treated with anti-VEGF therapy. Am J Ophthalmol. 2021;235:80-89. https://doi.org/10.1016/J.AJO. 2021.09.002.

17. Borrelli E, Sarraf D, Freund KB, Sadda SR. OCT angiography and evaluation of the choroid and choroidal vascular disorders. Prog Retin Eye Res. 2018;67:30-55. https://doi.org/10.1016/j. preteyeres.2018.07.002.

18. Parravano M, De Geronimo D, Scarinci F, et al. Progression of diabetic microaneurysms according to the internal reflectivity on structural optical coherence tomography and visibility on optical coherence tomography angiography. Am J Ophthalmol. 2019;198:8-16. https://doi.org/10.1016/j. ajo.2018.09.031.

19. Borrelli E, Palmieri M, Viggiano P, Ferro G, Mastropasqua R. Photoreceptor damage in diabetic choroidopathy. Retina. 2020;40(6):1062-69. https://doi.org/10.1097/IAE.0000000000002538.

20. Borrelli E, Sacconi R, Parravano M, et al. OCTA assessment of the diabetic macula: a comparison study among different algorithms. Retina. 2021;41(9):1799-808. https://doi.org/10.1097/IAE. 0000000000003145 .

21. Borrelli E, Parravano M, Costanzo E, et al. Using three-dimensional OCTA metrics improves repeatability on quantification of ischemia in eyes with diabetic macular edema. Retina. 2021;41(8): 1660-67. https://doi.org/10.1097/iae. 0000000000003077.

22. Couturier A, Rey P-A, Erginay A, et al. Widefield OCT-angiography and fluorescein angiography assessments of nonperfusion in diabetic 
retinopathy and edema treated with anti-vascular endothelial growth factor. Ophthalmology. 2019;126(12):1685-94. https://doi.org/10.1016/j. ophtha.2019.06.022.

23. Parravano M, Costanzo E, Borrelli E, et al. Appearance of cysts and capillary non perfusion areas in diabetic macular edema using two different OCTA devices. Sci Rep. 2020;10(1):800. https://doi.org/10. 1038/s41598-020-57680-w.

24. Schneider CA, Rasband WS, Eliceiri KW. NIH Image to ImageJ: 25 years of image analysis. Nature Method. 2012;9:671-5. https://doi.org/10.1038/ nmeth.2089.

25. Iafe NA, Phasukkijwatana N, Chen X, Sarraf D. Retinal capillary density and foveal avascular zone area are age-dependent: quantitative analysis using optical coherence tomography angiography. Investig Opthalmology Vis Sci. 2016;57(13):5780. https://doi.org/10.1167/iovs.16-20045.

26. Wang Q, Chan S, Yang JY, et al. Vascular density in retina and choriocapillaris as measured by optical coherence tomography angiography. Am J Ophthalmol. 2016;168:95-109. https://doi.org/10. 1016/j.ajo.2016.05.005.

27. Carnevali A, Sacconi R, Corbelli E, et al. Optical coherence tomography angiography analysis of retinal vascular plexuses and choriocapillaris in patients with type 1 diabetes without diabetic retinopathy. Acta Diabetol. 2017;54(7):695-702. https://doi.org/10.1007/s00592-017-0996-8.

28. Sim DA, Keane PA, Zarranz-Ventura J, et al. Predictive factors for the progression of diabetic macular ischemia. Am J Ophthalmol. 2013;156(4): 684-92. https://doi.org/10.1016/j.ajo.2013.05.033.

29. Sun Z, Tang F, Wong R, et al. OCT angiography metrics predict progression of diabetic retinopathy and development of diabetic macular edema: a prospective study. Ophthalmology. 2019;126(12): 1675-84. https://doi.org/10.1016/j.ophtha.2019. 06.016 .

30. Tsai ASH, Jordan-Yu JM, Gan ATL, et al. Diabetic macular ischemia: influence of optical coherence tomography angiography parameters on changes in functional outcomes over one year. Investig Ophthalmol Vis Sci. 2021;62:1. https://doi.org/10.1167/ IOVS.62.1.9.

31. Samara WA, Shahlaee A, Adam MK, et al. Quantification of diabetic macular ischemia using optical coherence tomography angiography and its relationship with visual acuity. Ophthalmology. 2017;124(2):235-44. https://doi.org/10.1016/j. ophtha.2016.10.008.

32. Ip MS, Domalpally A, Sun JK, Ehrlich JS. Long-term effects of therapy with ranibizumab on diabetic retinopathy severity and baseline risk factors for worsening retinopathy. Ophthalmology. 2015;122(2):367-74. https://doi.org/10.1016/j. ophtha.2014.08.048.

33. Hsieh YT, Alam MN, Le D, et al. OCT angiography biomarkers for predicting visual outcomes after ranibizumab treatment for diabetic macular edema. Ophthalmol Retina. 2019;3(10):826-34. https:// doi.org/10.1016/j.oret.2019.04.027.

34. Borrelli E, Sacconi R, Querques G. Re: Widefield OCT-angiography and fluorescein angiography assessments of nonperfusion in diabetic retinopathy and edema treated with anti-vascular endothelial growth factor (Ophthalmology 2019;126: 1685-1694). Ophthalmology. 2020;127(5):e32-4. https://doi.org/10.1016/J.OPHTHA.2020.01.003.

35. Neubauer AS, Kook D, Haritoglou C, et al. Bevacizumab and retinal ischemia. Ophthalmology. 2007;114(11):2096-2096.e2. https://doi.org/10. 1016/J.OPHTHA.2007.05.057.

36. Querques L, Parravano M, Sacconi R, Rabiolo A, Bandello F, Querques G. Ischemic index changes in diabetic retinopathy after intravitreal dexamethasone implant using ultra-widefield fluorescein angiography: a pilot study. Acta Diabetol. 2017;54(8):769-73. https://doi.org/10.1007/ s00592-017-1010-1.

37. Borrelli E, Parravano M, Querques L, et al. One-year follow-up of ischemic index changes after intravitreal dexamethasone implant for diabetic macular edema: an ultra-widefield fluorescein angiography study. Acta Diabetol. 2020;57(5):543-8. https://doi. org/10.1007/S00592-019-01435-1.

38. Booth G, Stalker TJ, Lefer AM, Scalia R. Mechanisms of amelioration of glucose-induced endothelial dysfunction following inhibition of protein kinase C in Vivo. Diabetes. 2002;51(5):1556-64. https:// doi.org/10.2337/diabetes.51.5.1556.

39. Tamura H, Miyamoto K, Kiryu J, et al. Intravitreal injection of corticosteroid attenuates leukostasis and vascular leakage in experimental diabetic retina. Invest Ophthalmol Vis Sci. 2005;46(4): 1440-4. https://doi.org/10.1167/iovs.04-0905. 